\title{
Understanding Inclusion from the Educators' Viewpoint
}

\author{
Jacqueline Lubin ${ }^{1 *}$ (Ed. D.) Fabienne S. Fernal' ${ }^{2}$ (M. Ed.) \\ 1.Teaching and Learning Department, College of Education, Tennessee State University, 3500 John A. Merritt \\ Blvd, Nashville, TN 37209 \\ 2.Ministry of Education, St. Lucia \\ *Email of corresponding author: jacyves@gmail.com
}

\begin{abstract}
Inclusion has been the preferred method of educating students with disabilities for several decades. However, the understanding of the concept of inclusion seems vast and diverse. The purpose of this study was to examine the perceptions of general and special educators from two geographic locations-United States and St. Lucia- on their understanding of inclusion. Findings indicate that the majority of educators' understanding of inclusion was based on the placement definition where instruction for students with disabilities occurs in the general education classroom. The main difference found was that most general educators used the placement definition of inclusion while special educators used the individual instruction and general instruction definitions as discussed by Göransson and Nilholm (2014). There was no major difference in responses between general and special educators based on context and state policy. Recommendations and implications for future practice are discussed.
\end{abstract}

Keywords: disabilities, education policy, global perspectives, inclusion, inclusive education, inclusive practice DOI: $10.7176 / \mathrm{JEP} / 12-3-04$

Publication date: January $31^{\text {st }} 2021$

\section{Introduction}

Globally, inclusive education has been the push in special education for more than four decades (Amor et al., 2019; Nilholm \& Göransson, 2017). International agencies have continuously formulated policies and legislation to guide inclusion (Amor et al., 2019; Gregory, 2018). This is evident in The Education for All Handicapped Children Act (1975) (now called in Individuals with Disabilities Education Improvement Act 2004) in the US which called for students to be educated in the least restrictive environment; The Warnock's Report (1978) in Great Britain which advocated for students with special needs to be educated in the general education classroom as much as possible; The Salamanca Statement and Framework for Action on Special Needs Education (1994) which called for the international community to endorse inclusive education where individuals with disabilities have access to general education settings with accommodations and child-centered pedagogy; and The New Zealand Disability Strategy (2001) which promoted the inclusion of individuals in their local schools. The agreement that solidified inclusion on the world scale was the Convention on the Rights of Persons with Disabilities (CRPD, 2006) Article 24 which stipulated that students with disabilities be educated in inclusive settings, that is, "ending segregation within educational settings by ensuring inclusive classroom teaching in accessible learning environments with appropriate support" (United Nations, 2006, p. 5). CRPD was the first legally binding international instrument that served to protect the inclusive rights of individuals with disabilities, and was signed by 164 nations, including the United States on July 30, 2009, and St. Lucia on September 22, 2011 (United Nations, 2020).

Despite the universal acceptance of stipulations, agreements, and the legal mandates on inclusion, the interpretation and implementation of the concept vary greatly among educators from and within countries (Amor et al. 2019, Nilholm \& Göransson, 2017, Magnússon, 2019). In fact, almost quarter of a century after the signing of CRPD, educators still have differing understanding/interpretations of inclusion (Ainscow, Dyson, \& Weiner, 2013/2014; Gregory, 2018; Lubin, 2020; Shyman, 2015). The exact meaning of inclusion has engendered fierce debates in countries around the world, including the United States and St. Lucia (Lubin, 2020;

Nilholm \& Göransson, 2017; Pellicano et al., 2018). It is evident that education discourse on inclusion lacks a clear universal definition.

There have been several explanations to the various viewpoints on inclusion, indicating that inclusion is a heterogeneous concept (Amor et al., 2019; Nilholm \& Göransson, 2017). Shyman (2015) explained that the differing views on inclusion may be attributed to the exceptionally broad explanation in literature, with wide application and specific verbiage. Magnússon (2019) elaborated that the diverse understandings of inclusion may be ascribed to the fact that one policy has to be adapted into diverse national and international context. Magnússon (2019) argues that the concept of inclusion is political idealism expected to be fulfilled in settings with different resources and organizational traditions

Inclusion has been defined as educating students with disabilities in the general education classroom for a $100 \%$ of the school day (Idol, 2006) to educating students as much as possible in general education settings with appropriate support (Mitchell, 2015). Presently most researchers concur that inclusion goes beyond placement to include a combination of appropriate services and supports such as access to curriculum, provision of adequate 
resources, appropriate school funding, and parental and family involvement (Alesech \& Nayar, 2020; Gregory, 2018; Kurth \& Gross 2014; Mitchell, 2015; Nilholm \& Göransson, 2017; Theoharis \& Causton, 2014). According to Shyman (2013) inclusion involves all students receiving primary mode of service and support in the general education environment, with the option for students with disabilities to receive services in their preferred environment with appropriate and accessible support.

Göransson and Nilholm (2014) explained that the definitions of inclusion fall under four categories. They include: (i) placement definition- defines inclusion as students with disabilities being educated in the general education classroom; (ii) individual instruction definition- explains inclusion as providing support for the social and academic needs of students with disabilities; (iii) general instruction definition- explicates inclusion as providing support for the social and academic needs of all students with and without disabilities; and (iv) community definition- describes inclusion as creating a conducive learning community where all students feel secure to reach their full potential. Göransson and Nilholm (2014) expounded that there is a hierarchical relationship among definitions as each category subsumes the preceding one. In a systematic review of literature across US and European journals on the meaning of inclusion, authors found that majority of empirical research articles used "placement definition" whereas theoretical/positional papers included "individual instruction definition," "general instruction definition" and "community definition" (Amor et al. 2019; Nilholm \& Göransson, 2017).

Inclusion arose as a positive reconceptualization of "integration" and "mainstreaming" (Nilholm, 2006). However, with varying understanding of this reconceptualized vision between practitioners and policy makers, the effective implementation of inclusive practices seems to be at risk (Alesech \& Nayar, 2020; Amr et al., 2016; Lubin, 2020). For a consensus on inclusion, the mindset of all stakeholders needs to recognized (Ansel et al., 2020). Without a unifying meaning and interpretation, educators may work towards differing goals as teachers' knowledge, attitudes and experiences are prominent to the success of inclusive education (Amr et al., 2016; Gregory, 2018).

The United States and St. Lucia are at different stages in the implementation of inclusive practices. With pivotal legislation, such as Education for All Handicapped Children Act (1975), Public Law 94-142 (later called Individuals with Disabilities Improvement Act, 2004), and No Child Left Behind (2001), the United States has pushed towards the use of inclusive practices for many decades. Policies in the US dictates that students with disabilities be educated in the least restrictive environment with increased access to the general education curriculum by providing support and accommodation (Morgan, 2015). Gregory (2018) explains that while students have access to schools, not all students have access to the curriculum. The US is a country with high national capital but funding for special education is tied to students being labeled as having a disability (Waddington \& Toepeke, 2014).

On the other hand, St. Lucia, one of the world's smallest developing countries, began the legislative push for inclusive practices by stipulating in the St. Lucia Education Act (1999) that "subject to available resources, all persons are entitled to receive an educational programme appropriate to their needs" (Section 14). The Act also guaranteed the provision of special education programmes for students (who are entitled) of compulsory school age (i.e., 5 - 15 years) "in the least restrictive and most enabling environment to the extent that resources permit" (St. Lucia Education Act, 1999, Section 83). Resources, such as adequate secondary school placement for all students, were obtained in 2006 when one of the goals of the Ministry of Education, to provide universal access to secondary education, was achieved (Chitolie- Joseph, 2014). Throughout its development, the island offered a bifurcated educational system where special education and regular education were offered in separate facilities. However, St. Lucia's developing nation status with low national capital places it in a precarious position to embrace policies, such as inclusion (prepared or not) as much of its educational funding is dependent on international financial organizations.

Although legal mandates and policies do not necessarily guarantee that inclusive practices are used, they do set a foundational guidance for educators with establishing shared beliefs and goals. Despite the difference in the timeline and roots of inclusion, educators in both settings tout that they use inclusive practices. As a result, the researchers sought to find out what inclusion looks like to educators in the United States (US) and St. Lucia (SLU). The purpose of this article is to report on findings from a study which investigated the perceptions of general and special educators from two geographic locations- United States and St. Lucia- on inclusion. One research question guiding this study was:

- What are the perceptions of special and general educators from the US and St. Lucia on inclusion? The data in connection to this question will be discussed in this article.

\section{Theoretical Framework}

In this study, we used the theoretical underpinnings of Pokewitz (2009) on "systems of reason" that govern educational policy to evaluate educators' understanding of inclusive education. Pokewitz (2009) defined "systems of reason" as rules and standards that guide practice. Using this definition, the theory implies that there are factors- 
individual factors, contextual factors, practical factors- that impact the implementation of inclusion. Therefore, similar to other researchers (e.g., Magnússon, 2019) we argue that the interpretation of inclusion differs based on context and state policy. Context refers to geographic location while state policy refers to ideological statements agreed upon by the state to improve educational practice. Inclusion is not a homogeneous ideology as most policies and legislation imply, but is a complex malleable issue. Inclusive practices are guided by layers of intertwining principles.

Pokewitz (2009) notion of "reason" explains that educational policies, in this case explanation/definition of inclusion, contain implicit assumptions on a consensus about how to educate the citizenry. We argue that these assumptions are impractical as they are based on ideological issues with contradicting goals which lead to differing interpretations from the policymakers and practitioners from various geographic locales. Inclusion policies, specifically international policies, that seek to create a global vision and universal mutual understanding, and applicability of how all students with disabilities should be educated fringes on the utopian world.

Special education systems in the US and St. Lucia are guided by local and international policies, agreements, laws, and stipulations. These policies form the cornerstone to what happens in the classroom. Understanding inclusion in these countries requires understanding "systems of reason" (Pokewitz, 2009, p. 307), i.e., understanding the complex patterns that impact implementation of inclusive practices. This study delves into understanding educators from US and St. Lucia perspectives on inclusion.

\section{Methodology}

Similar to other research a phenomenological qualitative approach was used to gain an understanding of general and special educators' perspectives on inclusion based on their experiences (Morgan, 2015). This approach allowed for describing participants' perceptions in a neutral manner as to maintain the validity of participants' lived experiences.

Participants were chosen through purposive sampling as it allowed for access to detailed, first-hand data regarding the perception of educators on inclusion (Birdwell et al., 2016). This method was suitable for the study as the goal was to gain a thorough understanding of teachers' experiences with inclusion. The study involves gathering data through three open-ended questions. Interview protocol included: (i) What is your understanding of inclusion?; (ii) What does inclusion look like in your classroom?; and (iii) Explain some teaching practices utilized in your inclusive classroom?. The participant sample included 19 educators from the mid-west region of the United States and 13 educators from St. Lucia (see Table 1).

$<$ insert Table 1 here $>$

Of the 32 participants, 12 were general education teachers and 20 were special education teachers. The majority were special educators as they were most likely to be familiar with inclusive practices. There were zero male special education participants from St. Lucia in the study because (as of the date of the study) all special educators in the K-12 system in St. Lucia was female. Most special educators in the US had less than a year ( $n=$ $5)$ to 1-3 years of experience $(n=5)$, while the majority in St. Lucia $(n=3)$ had more than seven years. Overall, almost half (47\%) of all participants had more than seven years teaching experience. In both the US $(n=10)$ and St. Lucia $(n=9)$, the majority $(59 \%)$ of participants taught at high school level, with no general educator in the US and no special educator in St. Lucia teaching grades four to six.

After obtaining approval from the Institutional Review Board at the principal researcher's institution, an email was sent to known educators with study description, consent form, and link to interview protocol. Data was collected through structured interview questions which were developed based on items in literature on inclusion (Morgan, 2015; Sharma et al., 2017). Interview protocol was administered virtually, and all responses were digitally recorded.

Data analysis was informed by the theoretical underpinnings of interpretative phenomenological analysis (Tuffour, 2017). Data were analyzed using four-stage inductive analysis and thematic analysis (Amr et al., 2016; Morgan, 2015). This included meticulous reading of interviews to familiarize with content, followed by developing a coding list. Codes were then integrated and synthesized under similar themes of: (i) placement definition; (ii) individual instruction definition; (iii) general instruction definition; and (iv) community definition. Participants' responses were categorized under these themes to gain a holistic picture of participants' understanding of inclusion. Lastly, responses were analyzed based on the theoretical underpinnings of Pokewitz (2009) on "systems of reason."

\section{Results}

Participants' responses on their understanding of inclusion were almost unified, despite differences in their context and state policy. There were three emerging themes on their interpretation of inclusion, i.e., placement definition, individual instruction definition, and general instruction definition.

Overall, the majority of participants from the US and St. Lucia viewed inclusion as placement of students with exceptionalities in general education settings (i.e., placement definition). Almost half, 47\% of participants $(n=15)$ defined inclusion as the location where students are educated, that is, students with disabilities being 
educated in the general education setting. In the US, one-third $(n=5)$ of special education teachers and half $(n=2)$ of general educators perceived inclusion as the location of instruction. In St. Lucia, 3\% $(n=1)$ of special education teachers and $88 \%(n=7)$ of general educators perceived inclusion as placement for instruction. Words such as students being taught in the "general education environment," "general education classroom," "general education setting," "general classroom," "regular education classroom" were found across in almost 50\% of participants' responses.

Approximately $28 \%(n=9)$ of participants explained inclusion as the provision of support for students with disabilities (i.e., individual instruction definition). They defined support as "making curriculum accessible" ( $n=$ 3), "adjusting curriculum" ( $n=5)$, "providing intervention" $(n=4)$, and "providing accommodations and modifications" $(n=2)$. Seven special educators (zero general educator) from the US and two special educators (zero general educators) from St. Lucia noted the individual instruction definition.

Few participants $(n=7)$ defined inclusion using the general instruction definition. Three special educators and one general educator from the US, and two special education teachers and one general education teacher from St. Lucia interpreted inclusion as providing support to all students. They described inclusion as "using universal design for learning" $(n=3)$, and "giving access to all students" $(n=6)$. Other interpretations of inclusion included generic explanations such as "to be part of a system" $(n=1)$. No participant interpreted inclusion as the community definition.

\section{Discussion}

The data from this study supports the findings of Amor et al. (2019) and Nilholm \& Göransson (2017) as the majority of participants (from both countries- the US and St. Lucia) provided the nominal definition of inclusioni.e., placement definition. Few participants identified the individual and general instruction definitions, while no one used the community definition of inclusion. Although literature has shown that there is a great disparity in the understanding of inclusion (Magnússon, 2019; Nilholm \& Göransson, 2017), this study highlights that the difference in interpretation is mainly between general and special teachers' perception of inclusion. There was almost no difference in interpretation of inclusion based on context and state policy.

Similar to the findings of previous studies, the data of this study indicate that the majority of educators' understanding of inclusion was limited to the physical placement of students with exceptionalities in the general education setting (Amr et al, 2016; Mitchell, 2015; Shyman, 2015). Almost half of all participants from the US and St. Lucia interpreted inclusion as the location of instruction rather than the nature of instruction and support within the environment. Teachers may have overwhelmingly defined inclusion as a form of placement as this is a more measurable, more objective, and more visible phenomenon. Researchers have explained that the placement definition helps make comparison easier, where school systems may easily indicate whether they are practicing inclusion (Magnússon, 2019; Nilholm \& Göransson, 2017). Nilholm (2006) argues that inclusion has a time dimension implying that stakeholders who want an immediate change to the school system may utilize the placement definition, whereas those with long term goals may use the theoretical definitions (such as community definition). In addition, the findings indicate that in both countries a larger percentage of general educators (i.e., $\mathrm{US}=50 \%$; SLU $=88 \%$ ) used the placement definition than any other interpretation. General educators' nominal understanding of inclusion may be attributed to their microscopic understanding of their roles as a general educator in an inclusive setting and/or limited exposure to inclusion in pre-and-post teacher preparation programs.

In relation to the individual instruction definition, only special educators (from both countries) understood inclusion as providing support to students with disabilities in the general education classroom. This may be because general and special educators identify their roles as separate and distinct, i.e., special educators perceive their principal role as supporting students with special needs while the general educators perceive their major responsibility as teaching the general education classroom (Birdwell et al., 2016; Morgan 2015). Birdwell et al. (2016) explained that special educators perceive their roles as supporting students with special needs and providing individualized instruction. Another reason why the data reflected that solely special educators interpreted inclusion as providing individual instruction to students with special needs may also be as a result of the different focus of teacher preparation programs, where special educators' preparation programs provide multiple courses on inclusion whereas general educators preparation programs provide minimal exposure to inclusive practices.

In regards to the general instruction definition, more special educators than general educators perceived inclusion as providing support for all students with and without disabilities. The results indicate that special educators are more likely to view inclusion as a form of support to students than general educators. This is concerning as research has shown that both general and special education teachers are needed for effective implementation of inclusion (Birdwell et al., 2016). In fact, general education teachers' attitude towards inclusive practices is a key factor into using inclusive practices efficaciously (Alesech \& Nayar, 2020; Gregory, 2018; Mitchell, 2015). Birdwell et al. (2016) elaborated that the relationship between the special and general educators is the leading predictor of whether inclusion is successful. They elucidated that without a positive attitude, inclusion goals as postulated in policies may not be achieved. For inclusion to work educators must have similar 
views on inclusion, work collaboratively, feel that students belong to their classroom, and have a desire to contribute to students' overall learning (Alesech \& Nayar, 2020; Gregory, 2018; Mitchell, 2015; Morgan, 2015).

No participant discussed the community definition, describing inclusion as creating a conducive learning community where all students feel secure to reach their full potential. This may be because the community definition is more idealistic, subjective, requires more resources, and so harder to measure and sustain. Also, the non-use of the community definition may be attributed to understanding Göransson and Nilholm (2014) inclusion definition hierarchy. The hierarchy may be compared to Maslow's hierarchy of needs where educators may need to understand inclusion at the lower levels (i.e., placement definition, individual instruction definition) before progressing to understanding inclusion at the highest level (i.e., community definition). The results convey that most educators' understanding is still at the lower level of the hierarchy. Therefore, additional education on the hierarchical explanations of inclusion may be required.

The results align with Pokewitz (2009) "systems of reason" that the theory of inclusion contains implicit assumptions, i.e., a gap between practice and theory. Although there was not a major difference between educators' understanding of inclusion based on geographic location and state policy, there seems to be a difference between the theoretical ideology of inclusion and the practical interpretation. The majority of practicing educators in this study defined inclusion as placement rather than the theoretical definition in the upper echelons of Göransson and Nilholm'a (2014) inclusion definition hierarchy. There was also a difference between the perceptions of special and general educators, where special educators seem to understand inclusion closer to theoretical principles than general educators' placement interpretation.

Overall, the results show that special educators were more likely to believe that inclusion was more than placement whereas the majority of general educators were focused on location of instruction. General education teachers had a limited knowledge of inclusion, with very few mentioning other aspects of inclusion as identified by researchers such as adapting curriculum, provision of adequate resources, appropriate school funding (Kurth \& Gross 2014; Mitchell, 2015; Nilholm \& Göransson, 2017; Theoharis \& Causton, 2014). The broader theoretical definitions of inclusion are more comprehensive and idealistic, and this may explain why most participants had a simplistic understanding of inclusion.

\section{Recommendations}

Several recommendations may be made to help educators gain a mutual understanding of inclusion. First, policymakers need to explain inclusion in a specific, measurable, and attainable manner in order to ensure that all teachers- both general and special educators have a collective understanding of inclusive practices. This would help alleviate the gap between policy and practice.

Second, educators, specifically general educators should be provided with more professional training on inclusion (Alesech \& Nayar, 2020; Moreno-Rodriguez et al., 2017). Pre-service programs have to increase course work and practice on working with students in inclusive settings. Courses on inclusion need not only be part of special education teacher preparation programs but be a more integral part of teacher preparation programs for general educators. Higher education faculty should not only teach coursework on inclusion but also model behaviors required in inclusive settings (Ticha et al., 2018). General educators may need more guidance and continuous professional development on providing accommodations and modifications, creating and implementing Individualized Education Programs (IEP), and using inclusive pedagogy.

Third, there should be more collaborative work between all stakeholders including curriculum developers, policymakers, general and special educators, families in developing and implementing policy on inclusion (Alesech \& Nayar, 2020; Ansell et al., 2020). The efforts should include a tsunamic shift in mindset on what inclusive education looks and not simply adopting international policy. Kiru (2019) explains that there is increased probability of buy-in and understanding of inclusion policy when all stakeholders are included and know their roles in the process. Morgan (2015) suggested a paradigm shift of resetting the educational culture.

The study contains limited qualitative data and so future research may delve into investigating the perspective of an increased number of general and special educators, and other stakeholders (such as principals, parents and students) from various locations on inclusion. Further investigation may examine how special and general educators' understanding of inclusion impact practice in the classroom.

\section{Limitations}

There are some limitations to the data presented from this study. The sample used in this study was very small, selected through purposive sampling, originated from specific regions (only one region in the United States and one island in the Caribbean) which limits the generalizability of findings. The study relied exclusively on selfreported data and so participants may have disclosed selective socially desirable responses. The proportion of general education teachers to special education teachers at the various grade levels may limit the clear perspective of educator's understanding of inclusion. 


\section{Conclusion}

The debate on inclusion continues with educators having multiple interpretations to this seemingly illusive policy. Ansel et al. (2020) explained that inclusion is a process, dynamic and tactical in nature. The understanding of inclusion ranges from specific measurable definition of placement to broader ideals of providing support to all students. This study corroborates findings of other studies on the lack of clarity in understanding of inclusion and shows the necessity to have an unequivocal explanation of inclusion (Amor et al., 2019; Nilholm \& Göransson, 2017). Although various global, state, and local legislation and policies sought to create a communal interpretation of inclusion, theory has yet to align with practice.

The perceptual differences on inclusion indicate that educators have varied beliefs and understanding about the education of students. The need towards practicing inclusion is urgent and should not be delayed by theoretical arguments. It is pivotal that the discourse focus on how best to practically and effectively meet the needs of students with disabilities. Therefore, educators should work towards a common understanding so as to use inclusive practices efficaciously.

\section{References}

Ainscow, M., Booth, T. \& Dyson, A. (2006). Improving schools, developing inclusion. Routledge.

Ainscow, M., Dyson, A., \& Weiner, S. (2013/2014). From exclusion to inclusion: A review of international literature on ways of responding to students with special educational needs in schools. En-clave Pegagogica, $13,13-130$.

Alesech, J., \& Nayar, S. (2020). Acceptance and belonging in New Zealand: Understanding inclusion for children with special needs. International Journal of Whole Schooling, 16(1), 84-116.

Amor, A.M., Hagiwara, M., Shogren, K. A., Thompson, J. R., Verdugo, M. A., Burke, K. M., \& Aguayo, V. (2019). International perspectives and trends in research on inclusive education: A systematic review. International Journal of Inclusive Education, 23(12), 1277-1295. https://10.1080/13603116.2018.1445304

Amr, M., Al-Natour, M., Al-Abdallat, B., \& Alkhamra, H. (2016). Primary School Teachers' Knowledge, Attitudes and Views on Barriers to Inclusion in Jordan. International Journal of Special Education, 31(1), $67-77$.

Ansell, C., Doberstein, C., Henderson, H., Siddiki, S., \& Hart, P. (2020). Understanding inclusion in collaborative governance: A mixed method approach. Policy and Society, 39(4), 570- 591. https://doi.org/10.1080/14494035.2020.1785726

Birdwell, J., Kupczynski, L., Mundy, M., \& Bain, S. (2016). A qualitative study of the perceptions of special education personnel about inclusive practices of students with disabilities. International Journal of Learning, Teaching and Educational Research, 15, 99- 110.

Chitolie-Joseph, E. (2014). Education for all 2015 national review report: Saint Lucia. Castries, St. Lucia: Ministry of Education, Human Resource Development and Labour- Corporate Planning Unit.

Göransson, K. \& Nilholm, C. (2014). Conceptual diversities and empirical shortcomings- A critical analysis of research on inclusive education. European Journal of Special Needs Education 29(3), 265- 280.

Gregory, J. (2018). Not my Responsibility: The impact of separate special education systems on educators' attitudes toward inclusion. Educational Policy Analysis and Strategic Research, 13(1), 127- 148.

Idol, L. (2006). Toward inclusion of special education students in general education: A program evaluation of eight schools. Remedial and Special Education, 27, 77- 94. https//doi: 10.1177/074132506020601

Kurth, J. A., \& Gross, M. (2014). The inclusion toolbox: Strategies and techniques for all teachers. Corwin Press.

Lubin, J. (2020). Roles of special educators in St. Lucia: Implications of policy and practice on inclusion. Journal of International Special Needs Education, 23(1), 33-44. https://doi.org/10.9782/JISNE-D-17-00035

Magnússon, G. (2019). An amalgam of ideals - images of inclusion in the Salamanca Statement. International Journal of Inclusive Education, 23(7-8), 677-690. https://doi: 10.1080/13603116.2019.1622805

Moreno-Rodriguez, R., Lopez, J. L., Carnicero, J. D., \& Sanchez, S. (2017). Teachers' perception on the inclusion of students with disabilities in the regular education classroom in Ecuador. Journal of Education and Training Studies, 5(9), 45- 53.

Morgan, P. S. (2015). General and special education high school teachers' perspectives of full membership for students with disabilities. Values and Ethics in Educational Administration, 11(3), 1- 9.

Mitchell, D. (2015). Inclusive education is a multi-faceted concept. Center for Educational Policy Studies Journal, $5(1), 9-30$.

Nilholm, C. (2006). Special education, inclusion and democracy. European Journal of Special Needs Education 21(4): 431-445. https://doi: 10.1080/08856250600957905.

Nilholm, C., \& Göransson, K. (2017). What is meant by inclusion? An analysis of European and North American journal articles with high impact. European Journal of Special Needs Education 32(3): 437-451. https://doi:10.1080/08856257.2017.1295638

Pellicano, L., Bölte, S., \& Stahmer, A. (2018). The current illusion of educational inclusion. Autism, 22(4), 386- 
387. https://doi: $10.1177 / 1362361318766166$

Popkewitz, T. (2009). Curriculum study, curriculum history, and curriculum theory: The reason of reason. Journal of Curriculum Studies, 41(3), 301-309.

Sharma, U., Loreman, T., \& Simi, J. (2017). Stakeholder perspectives on barriers and facilitators of inclusive education in the Solomon Islands. Journal of Research in Special Education Needs, 17(2), 143- 151. https://doi: 10.1111/1471-3802.12375

Shyman, E. (2013). Beyond equality in the American classroom: The case for inclusive education. Lexington Books.

Shyman, E. (2015). Toward a globally sensitive definition of inclusive education based in social justice. International Journal of Disability, Development and Education, 62(4), 351-362. http://dx.doi.org/10.1080/1034912X.2015.1025715.

St. Lucia Education

Act. http://www.unesco.org/education/edurights/media/docs/cc8deda54e8fc22b0ea96d3bc34760df95e34caf.pdf

Ticha, R., Abery, B., \& Kincade, L. (2018). Educational practices and strategies that promote inclusion: Examples from the U.S. Social Education, 6(2), 43- 62.

Theoharis, G., \& Causton, J. (2014). Leading inclusive reform for students with disabilities: A school- and system wide approach. Theory into Practice, 53, 82-97.

Tuffour, I. (2017). A critical overview of interpretative phenomenological analysis: A contemporary qualitative research approach. Journal of Healthcare Communications, 2 (52). https://doi: 10.4172/2472-1654.100093

United Nations. (2006). United Nations convention on the rights of persons with disabilities committee's general comment No. 4 on the right to inclusive education. http://www.right-to-education.org/resource/generalcomment-4-article-24-right-inclusive-education.

United Nations. (2020). Convention on the rights of persons with disabilities. Treaty Series, 2515, 1- 28. https://treaties.un.org/doc/Publication/MTDSG/Volume\%20I/Chapter\%20IV/IV-15.en.pdf

Waddington, L., \& Toepeke, C. (2014). Moving towards inclusive education as a human right: An analysis of international legal obligations to implement inclusive education in law and policy. Maastricht Faculty of Law Working Paper No. 2104-7. http://dx.doi.org/10.2139/ssrn.2535198

Table 1. Characteristics of Participants

\begin{tabular}{|c|c|c|c|c|}
\hline \multirow{3}{*}{ Characteristics } & \multicolumn{2}{|c|}{ United States } & \multicolumn{2}{|c|}{ St. Lucia } \\
\hline & General Educators & Special Educators & General Educators & Special Educators \\
\hline & $\mathrm{n}$ & $\mathrm{n}$ & $\mathrm{n}$ & $\mathrm{n}$ \\
\hline Number of Participants & 4 & 15 & 8 & 5 \\
\hline \multicolumn{5}{|l|}{ Sex } \\
\hline Male & 1 & 4 & 2 & 0 \\
\hline Female & 3 & 11 & 6 & 5 \\
\hline \multicolumn{5}{|l|}{ Years of Experience } \\
\hline$<$ a year & 1 & 5 & 0 & 0 \\
\hline $1-3$ years & 0 & 5 & 0 & 2 \\
\hline 4-7years & 0 & 3 & 1 & 0 \\
\hline $7+$ years & 3 & 2 & 7 & 3 \\
\hline \multicolumn{5}{|l|}{ Grades Taught } \\
\hline K-3 & 0 & 5 & 1 & 2 \\
\hline $4-6$ & 0 & 3 & 1 & 0 \\
\hline $7-12$ & 4 & 6 & 6 & 3 \\
\hline
\end{tabular}

